Wright State University

CORE Scholar

12-1-1999

\title{
Oxygen Pressure-Tuned Epitaxy and Optoelectronic Properties of Laser-Deposited ZnO Films on Sapphire
}

S. Choopun

R. D. Vispute

W. Noch

A. Balsamo

R. P. Sharma

See next page for additional authors

Follow this and additional works at: https://corescholar.libraries.wright.edu/physics

Part of the Physics Commons

\section{Repository Citation}

Choopun, S., Vispute, R. D., Noch, W., Balsamo, A., Sharma, R. P., Venkatesan, T., Iliadis, A., \& Look, D. C. (1999). Oxygen Pressure-Tuned Epitaxy and Optoelectronic Properties of Laser-Deposited ZnO Films on Sapphire. Applied Physics Letters, 75 (25), 3947-3949.

https://corescholar.libraries.wright.edu/physics/61

This Article is brought to you for free and open access by the Physics at CORE Scholar. It has been accepted for inclusion in Physics Faculty Publications by an authorized administrator of CORE Scholar. For more information, please contact library-corescholar@wright.edu. 


\section{Authors}

S. Choopun, R. D. Vispute, W. Noch, A. Balsamo, R. P. Sharma, T. Venkatesan, A. Iliadis, and David C. Look 


\title{
Oxygen pressure-tuned epitaxy and optoelectronic properties of laser-deposited ZnO films on sapphire
}

\author{
S. Choopun, R. D. Vispute, ${ }^{\text {a) }}$ W. Noch, A. Balsamo, R. P. Sharma, and T. Venkatesan \\ CSR, Department of Physics, University of Maryland, College Park, Maryland 20742 \\ A. Iliadis \\ Department of Electrical Engineering, University of Maryland, College Park, Maryland 20742 \\ D. C. Look \\ Semiconductor Research Center, Wright State University, Dayton, Ohio 45435
}

(Received 21 June 1999; accepted for publication 25 October 1999)

\begin{abstract}
Influence of oxygen pressure on the epitaxy, surface morphology, and optoelectronic properties has been studied in the case of $\mathrm{ZnO}$ thin films grown on sapphire (0001) by pulsed-laser deposition. Results of Rutherford backscattering and ion channeling in conjunction with atomic force microscopy clearly indicate that the growth mode, degree of epitaxy, and the defect density strongly depend on the oxygen background pressure during growth. It is also found that the growth mode and the defects strongly influence the electron mobility, free-electron concentration, and the luminescence properties of the $\mathrm{ZnO}$ films. By tuning the oxygen pressure during the initial and the final growth stages, smooth and epitaxial $\mathrm{ZnO}$ films with high optical quality, high electron mobility, and low background carrier concentration have been obtained. The implication of these results towards the fabrication of superlattices and controlled $n$ - and $p$-type doping is discussed.

(C) 1999 American Institute of Physics. [S0003-6951(99)01951-8]
\end{abstract}

$\mathrm{ZnO}$ is a direct-band-gap semiconductor with an energy gap of $3.3 \mathrm{eV}$ at room temperature (RT) and being considered as a futuristic material for UV and blue light-emitting devices. ${ }^{1-7}$ It has higher exciton binding energy $(60 \mathrm{meV}$ for $\mathrm{ZnO}$ versus $28 \mathrm{meV}$ for $\mathrm{GaN}$ ) and higher optical gain (300 $\left.\mathrm{cm}^{-1}\right)$ than $\mathrm{GaN}\left(100 \mathrm{~cm}^{-1}\right)$ at room temperature. ${ }^{1}$ Moreover, recent reports on externally pumped lasing in epitaxial $\mathrm{ZnO}$ thin films by Kawasaki et $a .^{2}$ and Bagnall et al. ${ }^{3}$ have stimulated great interest in $\mathrm{ZnO}$ material for realizing efficient, excitonic UV blue lasers at room temperature.

Two major challenges lie ahead to realize $\mathrm{ZnO}$-based current injection lasers and LEDs. One is to reduce the background carrier (free-electron) concentration in the $\mathrm{ZnO}$ films. The second is to achieve $p$-type conductivity. Previous attempts to achieve $p$-type doping with high hole concentration have been unsuccessful due to the compensation effect by a large background electron concentration. ${ }^{8-10}$

It is known that free electrons in $\mathrm{ZnO}$ are generated due to oxygen nonstoichiometry, possibly the formation of oxygen vacancies. ${ }^{11}$ Thus, oxygen vacancies must be removed to effect controlled doping. In order to reduce the oxygen vacancies, we recently carried out thin-film growth by pulsedlaser deposition in a higher oxygen background pressure of $10^{-1}$ Torr. The resulting films showed poor crystalline quality, rough surface morphology, low electron mobility, and poor luminescence properties. High-quality epitaxial films with low-defect densities (point defects and dislocations) and smooth surfaces and interfaces must be obtained for optical devices such as lasers and LEDs; thus, it is necessary to understand the growth mechanism that controls these factors

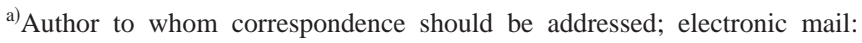
vispute@squid.umd.edu
}

and influences both the electrical and optical properties of the $\mathrm{ZnO}$ thin films.

In this letter, we discuss the effects of the oxygen background pressure on the growth, epitaxy, point defect chemistry, and structural, optical, and electrical transport properties of laser-deposited epitaxial $\mathrm{ZnO}$ films.

A description of our pulsed-laser deposition (PLD) setup for the growth of thin films of metal oxides and wide-bandgap semiconductors can be found elsewhere. ${ }^{12,13}$ The films were grown on sapphire (0001) at an optimized growth temperature of $750{ }^{\circ} \mathrm{C} .^{5}$ Thin-film growth was carried out at various oxygen background $\left(\mathrm{O}_{2}\right)$ pressures ranging from $10^{-5}$ to $10^{-1}$ Torr. In some cases, initial stages of growth (100-500 $\AA$ ) were carried out at a growth temperature of $750^{\circ} \mathrm{C}$ and $\mathrm{O}_{2}$ pressure of $10^{-4}$ Torr in order to grow high-quality epilayers, and then the $\mathrm{O}_{2}$ pressure was increased to $10^{-1}$ Torr. The $\mathrm{ZnO}$ layers were characterized by $\mathrm{x}$-ray diffraction (XRD), Rutherford backscattering spectrometry (RBS)/ion channeling, atomic force microscopy (AFM) transport measurement, UV-visible spectroscopy, and photoluminescence (PL) spectroscopy.

All of the $\mathrm{ZnO}$ layers grown in a wide range of $\mathrm{O}_{2}$ pressure $\left(10^{-5}-10^{-1}\right.$ Torr $)$ were found to be highly $c$-axis oriented. In the lower oxygen pressure regimes $\left(10^{-5}-10^{-4}\right.$ Torr), the films have a $c$-axis lattice parameter $0.25 \%$ larger than that of the bulk value. This is expected due to both oxygen deficiency and the compressive strain induced by the sapphire substrate (the lattice mismatch between sapphire and $\mathrm{ZnO}$ is $16.8 \%$ ). However, in the higher oxygen pressure regimes $\left(10^{-2}-10^{-1}\right.$ Torr), the $c$-axis lattice constant was found to approach the bulk value. The XRD $\omega$-rocking-curve full width at half maximum (FWHM) was $0.069^{\circ}$ for the film grown at an $\mathrm{O}_{2}$ pressure of 

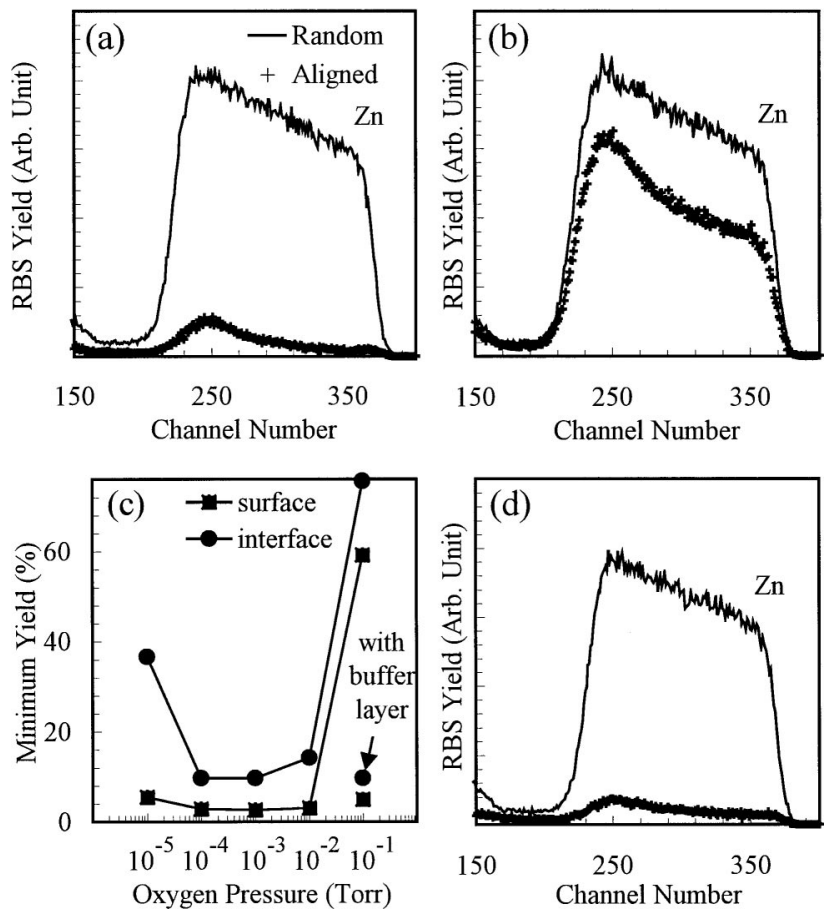

FIG. 1. Rutherford backscattering and ion channeling results for the $\mathrm{ZnO}$ films grown at various oxygen pressures: (a) $10^{-4}$ Torr, (b) $10^{-1}$ Torr, (c) minimum yield vs $\mathrm{O}_{2}$ pressure for growth, and (d) $10^{-1}$ Torr with a nucleation layer of $100 \AA$ grown at $10^{-4}$ Torr.

$10^{-4}$ Torr, and it was weakly dependent on the $\mathrm{O}_{2}$ pressure. The in-plane epitaxy, as determined by XRD $\phi$ scans of the $\mathrm{ZnO}(10 \overline{1} 1)$ planes, however, was strongly influenced by the oxygen pressure. The FWHM of the $\mathrm{ZnO}$ (1011) peak in the $\phi$ scan for the $\mathrm{ZnO}$ films grown at $10^{-4}$ and $10^{-1}$ Torr are $0.43^{\circ}$ and $0.78^{\circ}$, respectively. The increase of the FWHM in the $\phi$ scan for the film grown at higher $\mathrm{O}_{2}$ pressure clearly indicates a large misalignment of the $\mathrm{ZnO}$ grains and, hence, poor epitaxy.

The effects of $\mathrm{O}_{2}$ pressure on the degree of epitaxy and defect density were quantitatively measured by using RBS and ion channeling techniques and the results are shown in Fig. 1. In these measurements, $\chi_{\text {min }}$ (minimum yield), the ratio of the backscattered yield with the $1.5 \mathrm{MeV} \mathrm{He}^{+}$beam incident along [0001] (channeled) to that of a random direction, reflects the epitaxial quality (as well as defect density) of the film. Figures 1(a) and 1(b) show the aligned and random backscattering spectra for 5000- $\AA$-thick $\mathrm{ZnO}$ films grown at $10^{-4}$ and $10^{-1}$, respectively. Figure 1(c) shows the systematic dependence of $\chi_{\text {min }}$ near the surface and the interface $\left(\mathrm{ZnO} /\right.$ sapphire) on the $\mathrm{O}_{2}$ pressure. It can be seen that the $\chi_{\text {min }}$ near the surface region for the films grown in $\mathrm{O}_{2}$ pressure regimes of $10^{-4}-10^{-3}$ Torr is $\sim 2 \%-3 \%$ and is comparable to that of high-quality single crystals, while it is worse $(50 \%-60 \%)$ for the film grown at an $\mathrm{O}_{2}$ pressure of $10^{-1}$ Torr, indicating poor epitaxy. From Fig. 1(c), it should also be noted that the defect densities near the interface are strongly depended on the $\mathrm{O}_{2}$ pressure, indicating the influence of $\mathrm{O}_{2}$ during the initial stages of $\mathrm{ZnO}$ growth. The $\chi_{\text {min }}$ near the interface is about $10 \%-12 \%$ for the film grown at $10^{-4}$ Torr and increases substantially to $50 \%-60 \%$ as the $\mathrm{O}_{2}$ pressure increases to $10^{-1}$ Torr. The $\chi_{\text {min }}$ of $10 \%-12 \%$ for the epitaxial film is a result of the unavoidably high thread-
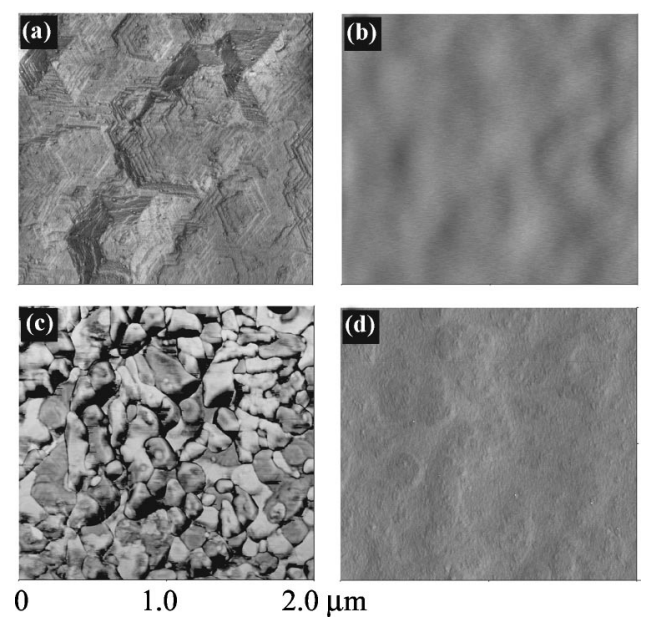

(d)

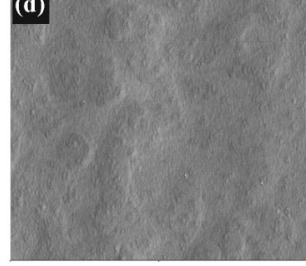

FIG. 2. AFM images of the $\mathrm{ZnO}$ films grown at various oxygen pressures: (a) $10^{-4}$ Torr, (b) $10^{-2}$ Torr, (c) $10^{-1}$ Torr, and (d) $10^{-1}$ Torr, with a nucleation layer of $100 \AA$ grown at $10^{-4}$ Torr.

ing dislocation density $\left(\sim 10^{9} / \mathrm{cm}^{2}\right),{ }^{6,7}$ due to a large lattice mismatch between the $\mathrm{ZnO}$ films and the sapphire. The increase in $\chi_{\text {min }}$ for the film grown in higher $\mathrm{O}_{2}$ pressure clearly indicates that the film contains additional defects, such as dislocations, low-angle grain boundaries, and interstitials.

Figure 2 shows the surface morphology of the $\mathrm{ZnO}$ films grown at various $\mathrm{O}_{2}$ pressures. The morphology of the films grown at $10^{-5}-10^{-4}$ Torr is dominated by a typical "honeycomb" -like structure with three-dimensional (3D) growth features as evidenced by well-faceted hexagons [Fig. 2(a)]. These features could be due to a high interfacial energy associated with the $\mathrm{ZnO}$ film on sapphire, a high surface mobility of the $\mathrm{Zn}$ adatom, and a substantial desorption of $\mathrm{Zn}$. We also observed a high density of atomic steps on the facets with a step height of about $5.0 \AA$, which corresponds to a single unit-cell height. These high densities of steps formed in a low-oxygen pressure during the initial stages of growth can significantly influence the growth of the $\mathrm{ZnO}$ film subsequently deposited, and is an important issue, which is discussed later. The transition towards the growth of a smooth film was found for an $\mathrm{O}_{2}$ pressure of $10^{-2}$ Torr. This change in growth mode results in a substantial reduction of $\mathrm{rms}$ roughness to 10-20 $\AA$ for a flat surface. A further increase of $\mathrm{O}_{2}$ pressure to $10^{-1}$ Torr showed an adverse effect on the surface morphology [Fig. 2(c)], with typical features of high nucleation densities, irregular grains with different sizes, and increased surface roughness to about $400 \AA$.

Now we discuss the influence of oxygen pressure on the optoelectronic properties of the $\mathrm{ZnO}$ films. Figure 3 shows the electrical properties, namely, the Hall mobility $(\mu)$ and carrier concentration $(n)$, for the $\mathrm{ZnO}$ films grown under various oxygen pressures. The highest electron mobility (72 $\mathrm{cm}^{2} / \mathrm{V} \mathrm{s}$ ) was obtained for the film grown at $10^{-4}-10^{-3}$ Torr, but that film also showed the highest carrier concentration $\left(7 \times 10^{17} / \mathrm{cm}^{3}\right)$. Further increase in $\mathrm{O}_{2}$ pressure reduces the Hall mobility, possibly as a result of electron scattering by the defects. Figures 4(a) and 4(b) show $80 \mathrm{~K}$ PL spectra for the $\mathrm{ZnO}$ films grown at $10^{-4}$ and $10^{-1}$ Torr, respectively. In both cases, the spectra indicate distinct peaks due to the free and bound $\left(D^{0} X\right)$ excitons and 

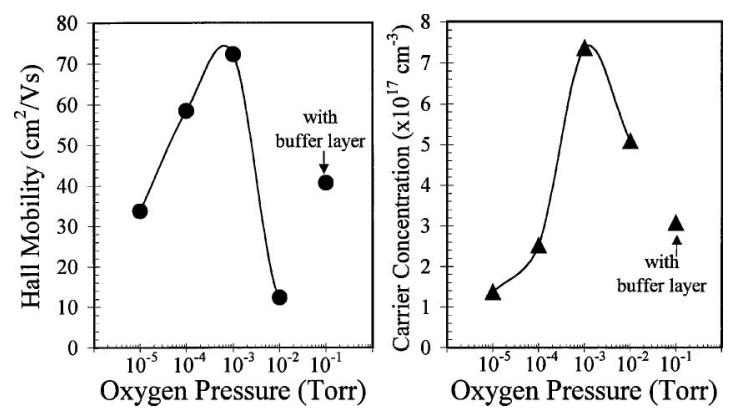

FIG. 3. Hall mobility and carrier concentration vs oxygen pressure for $\mathrm{ZnO}$ growth. For comparison, the data for the $\mathrm{ZnO}$ film grown at $10^{-1}$ Torr with the nucleation layer grown at $10^{-4}$ Torr are also provided.

features due to the donor-acceptor pair transitions at $3.32 \mathrm{eV}$ with phonon replicas at 3.25 and $3.18 \mathrm{eV}$ (see the inset of Fig. 4). The free- and bound-exciton peaks have FWHMs of 27 and $7 \mathrm{meV}$, respectively. The optical quality of the $\mathrm{ZnO}$ epilayer grown at $10^{-4}$ Torr is such that the excitonic luminescence intensity produced is two orders of magnitude higher than that of the textured film grown at $10^{-1}$ Torr. This indicates that a high concentration of defects in $\mathrm{ZnO}$ film affects the radiative processes. In addition, no green band (often attributed to structural defects in the $\mathrm{ZnO}$ ) near $500 \mathrm{~nm}$ is observed for the high-quality epilayers grown at $10^{-4}$ Torr, while it is clearly present for the textured film. We did not see any broadening in the exciton peaks, probably due to the very small radius $(\sim 17 \AA)$ of excitons in the $\mathrm{ZnO}$.

From the abovementioned results, we have clearly established that the growth of high-quality epitaxial $\mathrm{ZnO}$ films with smooth surface morphology and desirable electrical and optical properties have different sets of optimum oxygen pressure regimes. To circumvent these problems, a two-step growth process has been developed for the fabrication of high-quality $\mathrm{ZnO}$ films. In this process, the nucleation layer is grown at low-oxygen pressure $\left(10^{-4}\right.$ Torr $)$, which pro-

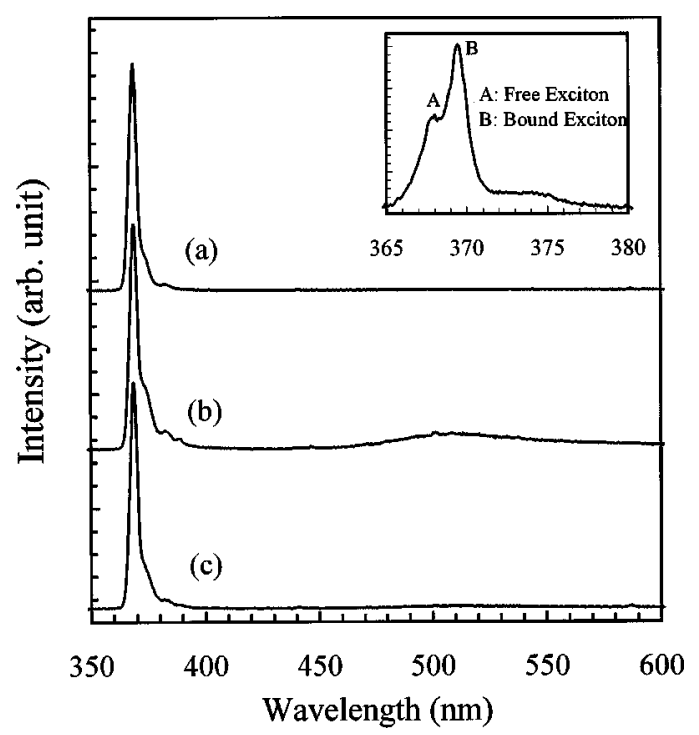

FIG. 4. $80 \mathrm{~K}$ PL spectra for the $\mathrm{ZnO}$ films grown at various oxygen pressures: (a) $10^{-4}$ Torr, (b) $10^{-1}$ Torr, and (c) $10^{-1}$ Torr with the nucleation layer grown at $10^{-4}$ Torr. The inset shows a high-resolution spectrum indicating free and bound excitons. duces a high-quality crystallographic template for subsequent growth of $\mathrm{ZnO}$ at a high-oxygen pressure $\left(10^{-1} \mathrm{Torr}\right)$. This two-step process produces $\mathrm{ZnO}$ films with superior epitaxy, resulting in ion channeling characteristics [Fig. 1(d)] similar to those in films grown in $10^{-4}$ Torr oxygen pressure. The surface morphology [Fig. 2(d)] and electrical properties are also improved as compared to those in films grown in $10^{-1}$ Torr. High-optical luminescence quality without a green band [Fig. 4(c)] is also achieved in these films. These results are important in the context of fabrication of highquality $\mathrm{ZnO}$-based heterostructures, superlattices, and quantum wells for which smoother films with good electrical and optical properties are required. Additionally, growth of $\mathrm{ZnO}$ films under high-oxygen pressure is desirable for $p$-type doping studies in order to avoid compensation due to oxygen vacancies.

In conclusion, we have shown that oxygen pressure strongly influences the growth and nucleation characteristics, defect densities, and electronic and luminescence properties of the $\mathrm{ZnO}$ films. A low-oxygen background pressure $\left(10^{-4}-10^{-3}\right.$ Torr $)$ in the initial stages of growth is critical for control of the epitaxy, while moderate-oxygen pressure $\left(10^{-2}\right.$ Torr) is required in the later stages to minimize the surface desorption process in order to achieve smooth films. The point defects caused by reduced surface mobility of the $\mathrm{Zn}$ adatoms, multiple nucleation, and dislocations, influence the electrical and optical properties of the films grown at high-oxygen pressure. By tuning the oxygen pressure during the initial and final stages of growth, it is thus possible to control desirable surface, interface, and optoelectronic properties of the films while maintaining high-quality epitaxy.

This work was supported by NSF-UMD MRSEC seed Grant No. DMR 9632521. The authors gratefully acknowledge the support of NSF through a contract supervised by Dr. Khosla. The authors would like to thank Dr. S. B. Ogale for helpful discussions.

${ }^{1}$ E. M. Wong and P. C. Searson, Appl. Phys. Lett. 74, 2939 (1999).

${ }^{2}$ M. Kawasaki, A. Ohtomo, I. Ohkubo, H. Koinuma, Z. K. Tang, P. Yu, G. K. L. Wang, B. P. Zhang, and Y. Segawa, Mater. Sci. Eng., B 56, 239 (1998).

${ }^{3}$ D. M. Bagnall, Y. F. Chen, Z. Zhu, T. Yao, S. Koyama, M. Y. Shen, and T. Goto, Appl. Phys. Lett. 70, 2230 (1997).

${ }^{4}$ D. C. Reynolds, D. C. Look, and B. Jogai, Solid State Commun. 99, 873 (1996)

${ }^{5}$ R. D. Vispute, V. Talyansky, S. Choopun, M. Downes, R. P. Sharma, T. Venkatesan, M. C. Wood, R. T. Lareau, K. A. Jones, and A. A. Iliadis, Appl. Phys. Lett. 70, 2735 (1997).

${ }^{6}$ R. D. Vispute, V. Talyansky, S. Choopun, R. P. Sharma, T. Venkatesan, M. He, X. Tang, J. B. Halpern, M. G. Spencer, Y. X. Li, L. G. SalamancaRiba, A. A. Iliadis, and K. A. Jones, Appl. Phys. Lett. 73, 348 (1998).

${ }^{7}$ J. Narayan, K. Dovidenko, A. K. Sharma, and S. Oktyabrsky, J. Appl. Phys. 84, 2597 (1998).

${ }^{8}$ K. Minegishi, Y. Koiwai, Y. Kikuchi, K. Yano, M. Kasuga, and A. Shimizu, Jpn. J. Appl. Phys., Part 2 36, L1453 (1997).

${ }^{9}$ Y. Sato and S. Sata, Thin Solid Films 281-282, 445 (1996).

${ }^{10}$ Y. Kanai, Jpn. J. Appl. Phys., Part 1 30, 703 (1991).

${ }^{11}$ Z. M. Jarzebski, in Oxide Semiconductors, edited by B. GrzybowskaSwierkosz and B. R. Pamplin (Pergamon, Oxford, 1973), Chap. 13, p. 228.

${ }^{12}$ R. D. Vispute, S. Choopun, R. Enck, A. Patel, V. Talyansky, R. P. Sharma, T. Venkatesan, W. L. Sarney, L. Salamanca-Riba, S. N. Andronescu, A. A. Iliadis, and K. A. Jones, J. Electron. Mater. 28, 275 (1999).

${ }^{13}$ Pulsed Laser Deposition of Thin Films, edited by D. Chrisey and G. Hubler (Wiley-Interscience, New York, 1994), and references therein. 